\title{
MMIMI Cardiac Procedures among American Indians and Alaska Natives compared to Non-Hispanic Whites Hospitalized with Ischemic Heart Disease in California
}

\author{
Stacey Jolly, MD, MAS ${ }^{1,4}$, Chi Kao, $P h D^{2}$, Andrew B. Bindman, MD ${ }^{1,2}$, and Carol Korenbrot, $P h D^{3}$ \\ 'Department of Medicine, Division of General Internal Medicine, University of California San Francisco, San Francisco General Hospital, San \\ Francisco, CA, USA; ${ }^{2}$ Philip R. Lee Institute for Health Policy Studies, University of California San Francisco, San Francisco, CA, USA; ${ }^{3}$ California \\ Rural Indian Health Board, Inc., Sacramento, CA, USA; ${ }^{4}$ Division of General Internal Medicine, Cleveland Clinic Medicine Institute, Cleveland, \\ $\mathrm{OH}, \mathrm{USA}$.
}

BACKGROUND: American Indians/Alaska Natives (AIAN) experience a high burden of cardiovascular disease with rates for fatal and nonfatal heart disease approximately twofold higher than the U.S. population.

OBJECTIVE: To determine if disparities exist in cardiac procedure rates among AIAN compared to non-Hispanic whites hospitalized in California for ischemic heart disease defined as acute myocardial infarction or unstable angina.

DESIGN: Cross-sectional study.

EVENTS: A total of 796 ischemic heart disease hospitalizations among AIAN and 90971 among non-Hispanic whites in 37 of 58 counties in California from 1998-2002.

MEASUREMENTS: Cardiac catheterization, percutaneous cardiac intervention, and coronary artery bypass graft surgery procedure rates from hospitalization administrative data.

MAIN RESULTS: AIAN did not have lower cardiac procedure rates for cardiac catheterization and percutaneous cardiac intervention compared to non-Hispanic whites (unadjusted OR 1.00, 95\% CI 0.87-1.16 and OR 1.04, 95\% CI 0.90-1.20, respectively). Adjustment for age, sex, comorbidities, and payer source did not alter the results (adjusted OR 0.95, 95\% CI 0.82-1.10 and OR 0.98, 95\% CI 0.85-1.14, respectively). We found higher odds (unadjusted OR 1.36, 95\% CI 1.09-1.70) for receipt of coronary artery bypass graft surgery among AIAN hospitalized for ischemic heart disease compared to non-Hispanic whites which after adjustment attenuated some and was no longer statistically significant (adjusted OR 1.26, 95\% CI 1.00-1.58).

CONCLUSION: AIAN were not less likely to receive cardiac procedures as non-Hispanic whites during hospitalizations for ischemic heart disease. Additional research is needed to determine whether differences in specialty referral patterns, patients' treatment preferences, or outpatient management may explain some of

Received November 26, 2008

Revised August 7, 2009

Accepted December 14, 2009

Published online January 27, 2010 the health disparities due to cardiovascular disease that is found among AIAN.

KEY WORDS: American Indian; Alaska Native; ischemic heart disease; cardiac procedures; health services; health disparities.

J Gen Intern Med 25(5):430-4

DOI: $10.1007 / \mathrm{s} 11606-009-1235-\mathrm{y}$

(c) Society of General Internal Medicine 2010

\section{INTRODUCTION}

Over the past 20 years, there has been a sharp rise in heart disease risk factors and heart disease among American Indians/Alaska Natives (AIAN). ${ }^{1-3}$ AIAN experience a high burden of cardiovascular disease with rates for fatal and nonfatal heart disease approximately two-fold higher than the U.S. population. ${ }^{2}$ Cardiovascular disease is the leading cause of death among AIAN in California. ${ }^{3}$

Progress has been made in the U.S. with a decline in deaths from heart disease thought to be related in part to coronary revascularization procedures. ${ }^{4-7}$ There is evidence that racial disparities exist among African-Americans and Hispanics compared to non-Hispanic whites in access to and the use of cardiac procedures which are thought to contribute to differences in morbidity and mortality. ${ }^{8-13}$ We are aware of very few previously published studies that compare the cardiovascular procedure rates among AIAN with other racial groups. ${ }^{14,15}$ One found that in some geographic regions of the U.S., AIAN have lower rates of coronary revascularization than whites in the setting of acute myocardial infarction. ${ }^{14}$ However, this study did not include California, the state with the largest number of AIAN in the country. ${ }^{16}$ That study did not include California because the national hospital and Indian Health Service databases used in the study could identify only a small fraction of hospitalizations for AIAN in California.

We aimed to determine whether differences existed in cardiac procedure rates among AIAN compared to nonHispanic whites hospitalized for ischemic heart disease, defined as acute myocardial infarction or unstable angina, in California. To assure sufficient number of hospitalizations we used the California state database for all hospitalizations, and used Indian Health Service data to identify the AIAN more accurately in that database. Thus, we focused on the 
37 counties within California included in the Indian Health Service data.

\section{METHODS}

We conducted a cross-sectional secondary data analysis of hospitalizations at non-federal hospitals in California. We used the California patient discharge database from the California Office of Statewide Health Planning and Development (OSHPD) for the years 1998 to 2002 . This database includes information about admission and discharge dates, patient demographics, diagnosis codes, and expected payer source status for all hospitalizations in non-federal hospitals within California. OSHPD applies several hundred audit rules to patient discharge data to enhance the validity of the data. ${ }^{17}$ Nonetheless, in many databases, such as administrative patient discharge data, AIAN are often misclassified. ${ }^{1,18,19}$

In order to more accurately define AIAN hospitalized in California, we used a state discharge database that had previously been linked with a database of AIAN who used Tribal Health Programs funded by the Indian Health Service serving 37 of the 58 counties of California. ${ }^{18}$ California patient discharge data was linked with the National Patient Information Reporting System list of active users of the Indian Health Service for the corresponding time period of 1998 to 2002 by the California Department of Health Services. Active users of Tribal Health Programs are defined as AIAN enrolled in federally recognized tribes who live on or near tribal lands and who had at least one visit to a Tribal Health Program clinic in the year reported or in the two years prior. ${ }^{18}$ Over 66,000 AIAN in California were active users of the tribally owned and operated Tribal Health Programs. ${ }^{20}$ Tribal Health Programs provide comprehensive ambulatory primary care; but access to specialty care is limited in part because of insufficient funding. ${ }^{21,22}$ There are no tribal or Indian Health Service hospitals in California. The California Area Office of the Indian Health Service and the California Rural Indian Health Board of Directors approved the project that linked the hospital data.

\section{STUDY POPULATION}

We included hospital discharges from non-federal hospitals for which the race of the patient was identified in the discharge data as non-Hispanic white or AIAN and residence was in the 37 counties served by Tribal Health Programs. We supplemented the AIAN study group with hospitalizations in which the race of the patient was not AIAN in the discharge data but was an active user in the linked Indian Health Service data. After identification of the study group, the comparison group of nonHispanic whites consisted of hospitalizations in the patient discharge database with "white or Caucasian" in the race field and "not Hispanic" in the ethnicity field.

We included those hospitalizations with a primary diagnosis of ischemic heart disease ${ }^{8,23}$ which we defined as acute myocardial infarction (AMI) or unstable angina and whose patient age was greater than or equal to 30 years. We focused on these two acute ischemic conditions because they typically require treatment in a hospital and therefore these events are less susceptible to differential admission decisions by patient race that could bias observed rates of cardiac procedures. From these hospitalizations we excluded those with a maternity related secondary diagnostic code (630-677, V27). Ische- mic heart disease was defined by the following ICD-9 diagnostic codes: acute myocardial infarction (410, 410.0410.9 ) without a 5 th digit code of " 2 " in order to exclude those who were readmitted within 8 weeks for AMI; and unstable angina (411.1).

\section{OUTCOME}

We examined three cardiac procedures of interest: cardiac catheterization, percutaneous coronary intervention, and coronary artery bypass graft surgery. Receipt of a cardiac procedure was defined by ICD-9 coding of a primary procedure and up to twenty secondary procedures possible per hospitalization. We used ICD-9 procedure codes to define: cardiac catheterization $(37.22,37.23,88.53-88.57)$; percutaneous coronary intervention $(37.22,37.23,88.53-88.57,36.06$, $36.00-36.03,36.05)$; and coronary artery bypass graft surgery (36.1, 36.3, 36.10-36.19). A hospitalization could contribute zero, one, two, or three cardiac procedures.

\section{STATISTICAL ANALYSIS}

We calculated the number of cardiac procedures during a hospitalization for ischemic heart disease for AIAN and nonHispanic whites. We then compared these cardiac procedure ratios using logistic regression to estimate the odds ratios and their corresponding 95\% confidence intervals for receipt of each of these procedures among those with ischemic heart disease. Recognizing that there could be potential differences in the characteristics and health of AIAN and non-Hispanic white patients who are hospitalized for ischemic heart disease, we controlled for age, sex, and comorbidity. We incorporated age as a categorical variable in our logistic model grouped as $30-44,45-54,55-64$, and 65 years of age or older. We used the Elixhauser Method to adjust for 29 comorbid conditions. ${ }^{24}$ In addition, we examined whether hospitalization payer source explained potential differences in the receipt of a cardiac procedure. We categorized hospitalization payers as Medicare, Medicaid, private insurance, other government coverage, and uninsured.

\section{RESULTS}

In California, from 1998-2002, there were 796 hospitalizations among AIAN and 90,971 among non-Hispanic whites for ischemic heart disease in the 37 study counties. Of the 796 hospitalizations for ischemic heart disease among AIAN, 557 of the hospitalizations were among active users of the Tribal Health Programs, and 396 of those hospitalizations had race codes other than AIAN in the unlinked California patient discharge data. Thus, 50\% (396/796) of the hospitalizations for AIAN for ischemic heart disease in the 37 counties were identified through the linkage of the patient discharge data with Indian Health Service data.

AIAN hospitalized for ischemic heart disease were younger on average than non-Hispanic whites hospitalized with the conditions acute myocardial infarction or unstable angina (Table 1). Ischemic heart disease hospitalizations for AIAN were more likely to be paid by Medicaid and less likely paid by Medicare compared with those for non-Hispanic whites. The 
Table 1. Characteristics of AIAN and Non-Hispanic White Ischemic Heart Disease Hospitalizations in California, 1998-2002

\begin{tabular}{|c|c|c|c|}
\hline & $\begin{array}{l}\text { American Indian/ } \\
\text { Alaska Native }\end{array}$ & $\begin{array}{l}\text { Non- } \\
\text { Hispanic } \\
\text { White }\end{array}$ & $\begin{array}{l}\text { Chi-Square } \\
\text { p-value }\end{array}$ \\
\hline & $N=796$ & $\mathrm{~N}=90,791$ & \\
\hline Age & No. (\%) & No. (\%) & \\
\hline 30-44 years & $57(7)$ & $3747(4)$ & $<0.0001$ \\
\hline $45-54$ years & $176(22)$ & $11,813(13)$ & \\
\hline $55-64$ years & $210(27)$ & 16,846 (19) & \\
\hline 65 years or older & $353(44)$ & $58,385(64)$ & \\
\hline \multicolumn{4}{|l|}{ Sex } \\
\hline Male & $471(59)$ & $54,544(60)$ & 0.603 \\
\hline Female & $325(41)$ & $36,247(40)$ & \\
\hline \multicolumn{4}{|c|}{ Hospitalization payer source* } \\
\hline Medicare & $378(47)$ & $53,899(59)$ & $<0.0001$ \\
\hline Medi-Cal & $97(12)$ & $3619(4)$ & \\
\hline Private & 232 (29) & $28,014(31)$ & \\
\hline $\begin{array}{l}\text { Other } \\
\text { government }\end{array}$ & $20(3)$ & $1677(2)$ & \\
\hline $\begin{array}{l}\text { No coverage/ } \\
\text { uninsured }\end{array}$ & $69(9)$ & $3542(4)$ & \\
\hline \multicolumn{4}{|c|}{ Ischemic heart disease } \\
\hline $\begin{array}{l}\text { Acute myocardial } \\
\text { infarction }\end{array}$ & $652(82)$ & $79,695(88)$ & $<0.0001$ \\
\hline Unstable angina & $144(18)$ & $11,096(12)$ & \\
\hline
\end{tabular}

${ }^{*} N=90,751$ for $N H W$ due to missing values

majority of ischemic heart disease hospitalizations were for AMI among both groups.

Comorbidities for ischemic heart disease hospitalizations were similar among AIAN compared to non-Hispanic whites (Table 2). However, AIAN as compared to non-Hispanic whites were more likely to have uncomplicated or complicated diabetes. Renal failure and obesity were also more common among AIAN as compared to non-Hispanic whites.

Cardiac catheterizations occurred in less than half of the hospitalizations for ischemic heart disease for both AIAN (40.9\%, 326/796) and non-Hispanic whites (40.8\%, 37,108 / $90,791)$. Similarly, $43.3 \%(345 / 796)$ of the hospitalizations for ischemic heart disease among AIAN had a percutaneous coronary intervention and $42.3 \%(38,459 / 90,791)$ of the hospitalizations among non-Hispanic whites. Coronary artery bypass graft surgery occurred in $10.9 \%$ of ischemic heart disease hospitalizations for AIAN $(87 / 796)$ and $8.2 \%$ for nonHispanic whites $(7517 / 90,791)$.

In unadjusted and adjusted analyses, the odds of having a cardiac catheterization or percutaneous coronary intervention during a hospitalization for acute ischemic heart disease were statistically similar between AIAN and non-Hispanic (Table 3). However, AIAN had statistically significant higher odds of receiving coronary artery bypass graft surgery than non-Hispanic whites during a hospitalization for ischemic heart disease in the unadjusted analysis. These results were no longer statistically significant following adjustment for other demographic characteristics, co-morbidities and payer source.

\section{DISCUSSION}

There is very limited information on disparities in cardiac procedure use among AIAN, a population that is culturally diverse and dispersed throughout the United States, but AIAN have one of the highest prevalence rates of cardiovascular disease. ${ }^{1,2,25}$ We found that during hospitalizations for ischemic heart disease AIAN had similar rates of the cardiac procedures, cardiac catheterization and percutaneous coronary intervention, both before and after adjustment for covariates as non-Hispanic whites. However, for coronary artery bypass graft surgery, we found higher rates among AIAN as compared to non-Hispanic whites hospitalized for ischemic heart disease in unadjusted analyses that then attenuated and were no longer significant after adjustment for age, sex, comorbidities, and hospitalization payer source.

Our results differ from a previous study that found AIAN less likely to receive a cardiac catheterization or percutaneous coronary intervention in the setting of an acute myocardial infarction as compared to whites in specific geographic regions of the U.S. ${ }^{14}$ This same study also found that AIAN with

Table 2. Comorbidities for Ischemic Heart Disease Hospitalizations Among AIAN and Non-Hispanic Whites in California, 1998-2002

\begin{tabular}{|c|c|c|}
\hline & $\begin{array}{l}\text { American } \\
\text { Indian/ } \\
\text { Alaska Native }\end{array}$ & Non-Hispanic White \\
\hline & $N=796$ & $\mathrm{~N}=90,791$ \\
\hline & No. (\%) & No. (\%) \\
\hline Congestive heart failure & $6(0.8)$ & $517(0.6)$ \\
\hline Valvular disease & $2(0.3)$ & $137(0.2)$ \\
\hline $\begin{array}{l}\text { Pulmonary circulation } \\
\text { disorders }\end{array}$ & $0(0)$ & $25(0.03)$ \\
\hline $\begin{array}{l}\text { Peripheral vascular } \\
\text { disorders }\end{array}$ & $72(9.1)$ & $6893(7.6)$ \\
\hline Hypertension & $428(53.8)$ & $43,752(48.2)^{* *}$ \\
\hline Paralysis & $17(2.1)$ & $1913(2.1)$ \\
\hline $\begin{array}{l}\text { Other neurological } \\
\text { disorders }\end{array}$ & $23(2.9)$ & 3925 (4.3)* \\
\hline Chronic pulmonary disease & $171(21.5)$ & $18,274(20.1)$ \\
\hline Diabetes, uncomplicated & $260(32.7)$ & $18,858(20.8)^{* * *}$ \\
\hline Diabetes, complicated & $86(10.8)$ & $3899(4.3)^{* * * *}$ \\
\hline Hypothyroidism & $57(7.2)$ & $7678(8.5)$ \\
\hline Renal failure & $58(7.3)$ & $3356(3.7)^{* * * *}$ \\
\hline Liver disease & $13(1.6)$ & $587(0.7)^{* * * *}$ \\
\hline $\begin{array}{l}\text { Peptic ulcer disease } \\
\text { excluding bleeding }\end{array}$ & $2(0.3)$ & $139(0.2)$ \\
\hline $\begin{array}{l}\text { Acquired immune } \\
\text { deficiency syndrome }\end{array}$ & $0(0)$ & $87(0.1)$ \\
\hline Lymphoma & $1(0.1)$ & $280(0.3)$ \\
\hline Metastatic cancer & $4(0.5)$ & $588(0.7)$ \\
\hline $\begin{array}{l}\text { Solid tumor without } \\
\text { metastasis }\end{array}$ & $6(0.8)$ & $1188(1.3)$ \\
\hline $\begin{array}{l}\text { Rheumatoid arthritis/ } \\
\text { collagen vascular disease }\end{array}$ & $17(2.1)$ & $1662(1.8)$ \\
\hline Coagulopathy & $13(0.6)$ & $1720(1.9)^{*}$ \\
\hline Obesity & 103 (12.9) & $6681(7.4)^{* * * *}$ \\
\hline Weight loss & $9(1.1)$ & $707(0.8)$ \\
\hline Fluid and electrolyte disorders & $80(10.1)$ & $9720(10.7)$ \\
\hline Blood loss anemia & $10(1.3)$ & $928(1.0)$ \\
\hline Deficiency anemias & $82(10.3)$ & $8753(9.6)$ \\
\hline Alcohol abuse & $27(3.4)$ & $1805(2.0)^{* *}$ \\
\hline Drug abuse & $6(0.8)$ & $770(0.9)$ \\
\hline Psychoses & $11(1.4)$ & $1102(1.2)$ \\
\hline Depression & $23(3)$ & $3172(3.5)$ \\
\hline
\end{tabular}

"chi-square $p$-value $<0.05$

*** chi-square p-value $<0.01$

${ }^{* * *}$ chi-square $p$-value $<0.001$ 
Table 3. Cardiac Procedure Odds Ratios for AIAN versus NonHispanic Whites during Ischemic Heart Disease Hospitalizations, California, 1998-2002

\begin{tabular}{|c|c|c|c|c|}
\hline & Unadjusted & $\begin{array}{l}\text { Adjusted } \\
\text { for age } \\
\text { and sex }\end{array}$ & $\begin{array}{l}\text { Adjusted for } \\
\text { age, sex, } \\
\text { comorbidities }\end{array}$ & $\begin{array}{l}\text { Adjusted for } \\
\text { age, sex, } \\
\text { comorbidities and } \\
\text { hospitalization } \\
\text { payer source }\end{array}$ \\
\hline & $\begin{array}{l}\mathrm{OR}^{a} \\
\quad(95 \% \mathrm{CI})\end{array}$ & $\begin{array}{l}\mathrm{OR}^{a} \\
\quad(95 \% \mathrm{CI})\end{array}$ & $\begin{array}{l}\mathrm{OR}^{a} \\
\quad(95 \% \mathrm{CI})\end{array}$ & $\begin{array}{l}\mathrm{OR}^{a} \\
\quad(95 \% \mathrm{CI})\end{array}$ \\
\hline $\mathrm{CC}^{b}$ & $\begin{array}{l}1.00 \\
(0.87-1.16)\end{array}$ & $\begin{array}{l}0.89 \\
(0.77- \\
1.02)\end{array}$ & $\begin{array}{l}0.93 \\
(0.80-1.07)\end{array}$ & $\begin{array}{l}0.95 \\
(0.82-1.10)\end{array}$ \\
\hline $\mathrm{PCI}^{c}$ & $\begin{array}{l}1.04 \\
(0.90-1.20)\end{array}$ & $\begin{array}{l}0.92 \\
(0.85- \\
1.06)\end{array}$ & $\begin{array}{l}0.96 \\
(0.83-1.11)\end{array}$ & $\begin{array}{l}0.98 \\
(0.85-1.14)\end{array}$ \\
\hline $\mathrm{CABG}^{d}$ & $\begin{array}{l}1.36 \\
(1.09-1.70)^{* *}\end{array}$ & $\begin{array}{l}1.35 \\
(1.08- \\
1.69)^{* *}\end{array}$ & $\begin{array}{l}1.25 \\
(1.00-1.57)\end{array}$ & $\begin{array}{l}1.26 \\
(1.00-1.58)\end{array}$ \\
\hline
\end{tabular}

${ }^{a} \mathrm{OR}=$ Odds Ratio; $\mathrm{CI}=$ Confidence Interval

${ }^{b} \mathrm{CC}=$ Cardiac Catheterization

${ }^{c} \mathrm{PCI}=$ Percutaneous Coronary Intervention

${ }^{d} C A B G=$ Coronary Artery Bypass Graft Surgery

" $p$-value $<0.05$

$p$-value $<0.01$

diabetes were less likely to get a coronary artery bypass surgery, but there was no difference among those without diabetes as compared to whites. ${ }^{14}$ California was not included in that study, because it was done using an Indian Health Service hospitalization database and California does not have any an Indian Health Service funded hospital, and California has the lowest per capita Indian Health Service funds for financing hospitalizations in other hospitals. ${ }^{14,18,26}$

It is possible that the availability of the Tribal Health Programs in the California counties we studied contributed to our finding of no disparities in cardiac procedures during a hospitalization for ischemic heart disease between AIAN and non-Hispanic whites. Even though the Tribal Health Programs are severely limited in the amount of specialist or hospital care they can purchase for their users, it may be that these programs play a significant role in informing and empowering AIAN about their health care choices. Alternatively, our findings may reflect a difference in the practice patterns between Indian Health Service hospitals previously studied outside of California and the use of non Indian Health Service hospitals by AIAN in California. While we do not have data outside of California, it is worth noting that our findings are also consistent with a separate study that used a voluntary national registry and found that AIAN hospitalized for acute ischemic heart disease were as likely as whites to receive a cardiac catheterization and percutaneous coronary intervention. ${ }^{15}$

The administrative data in our study lacked key clinical information, such as the number of coronary vessels found to be atherosclerotic during cardiac catheterization or number of vessels bypassed during coronary artery bypass graft surgery. However, the Strong Heart Study, a longitudinal cardiovascular cohort conducted among AIAN in the Southwest, Northern Plains, and Oklahoma, showed that the majority of coronary artery disease found was related to diabetes. ${ }^{2}$ Given that patients with diabetes tend to have more severe three-vessel coronary artery disease, it maybe that AIAN had more severe coronary artery disease than non-Hispanic whites that we were unable to account for in adjustments and this may explain why our data showed higher rates of coronary artery bypass graft surgery among the AIAN group.

Though our study did not show a disparity in cardiac procedures during ischemic heart disease hospitalizations for AIAN compared to non-Hispanic whites in California, it has several limitations that are important to note. First, our analysis is based on administrative data. The reliability of racial coding in administrative databases is a concern especially for races other than white, and AIAN are often misclassified. ${ }^{1,18,19}$ However, we were able to overcome some of those challenges in our study by linking a file of AIAN active users of Indian Health Service funded care through Tribal Health Programs that operate in 37 counties with a statewide hospital discharge database. ${ }^{18}$

Second, the unit of analysis and denominator for our analyses is hospitalizations and not individuals. We might have found a different result had we been able to study individuals. If for example, non-Hispanic whites were more likely than AIAN to have multiple hospitalizations to manage an episode of ischemic heart disease this could create the appearance of a similarity in the use of cardiac procedures between AIAN and non-Hispanic whites when an analysis at the person level might suggest a disparity. We were unable to analyze the data using the individual as the unit of analysis because we were not provided with individual identifiers in the OSHPD hospital discharge file that was linked with users of the Tribal Health Program. However, we did limit our sample to those acute ischemic heart disease admissions that had a 5 th digit of "1" to signify initial episode of care in an attempt to minimize influence from multiple hospitalizations.

Third, we cannot account for clinical appropriateness using the hospitalization administrative data, and thus even though we have found a similarity in the use of cardiac procedures between AIAN and non-Hispanic whites hospitalized for ischemic heart disease, the rates we observed per hospitalization may reflect underuse in one group and overuse in the other. ${ }^{27,28}$ Research on health care disparities among other racial and ethnic groups has tended to find greater degrees of underuse in minority populations and overuse in non-Hispanic whites. ${ }^{29,30}$ Also we cannot account for patients who may have been offered a cardiac procedure and subsequently refused. ${ }^{31,32}$

Further work is needed to elucidate the mechanisms of high mortality among AIAN from ischemic heart disease. We need to understand the prevalence of cardiac risk factors, the incidence of the disease, and the factors that influence the receipt of and continued adherence to beneficial treatments. These include specialty referral patterns and patients' treatment preferences, both as inpatients and outpatients. We will need new and continued cooperation among tribes, agencies, and academic institutions to address these critical health care issues and questions.

ACKNOWLEDGEMENTS: Dr. Jolly was supported by Health Resources and Services Administration Faculty Development in Primary Care Grant D55HP05165 for this study. Drs. Korenbrot and Kao's effort on this study was made possible through Grant Number U26IHS300008A from the Indian Health Service (IHS) with the support of the Agency for Healthcare Research and Buality (AHRQ). Its contents are solely the responsibility of the authors and do not necessarily represent the official views of the IHS or AHRQ.

Conflict of Interest: None disclosed. 
Corresponding Author: Stacey Jolly, MD, MAS; Division of General Internal Medicine, Cleveland Clinic Medicine Institute, 9500 Euclid Avenue/ G-10, Cleveland, OH 44195, USA (e-mail: jollys@ccf.org).

\section{REFERENCES}

1. Rhoades DA. Racial misclassification and disparities in cardiovascular disease among American Indians and Alaska Natives. Circulation. 2005;111(10): 1250-6.

2. Howard BV, Lee ET, Cowan LD, et al. Rising tide of cardiovascular disease in American Indians. The Strong Heart Study. Circulation. 1999;99(18):2389-95.

3. Johnson S, Kao C, Korenbrot $\mathbf{C}$. Disparities in mortality rates of American Indians and Alaska Natives in California, 1998 to 2002. California Tribal Epidemiology Center, American Indian Health in California 2006; 1(1)

4. Alderman EL, Bourassa MG, Cohen LS, et al. Ten-year follow-up of survival and myocardial infarction in the randomized Coronary Artery Surgery Study. Circulation. 1990;82(5):1629-46.

5. Chaitman BR, Rosen AD, Williams DO, et al. Myocardial infarction and cardiac mortality in the Bypass Angioplasty Revascularization Investigation (BARI) randomized trial. Circulation. 1997;96(7):2162-2170.

6. Pocock SJ, Henderson RA, Clayton T, Lyman GH, Chamberlain DA. Quality of life after coronary angioplasty or continued medical treatment for angina: three-year follow-up in the RITA-2 trial. Randomized Intervention Treatment of Angina. J Am Coll Cardiol. 2000;35(4):907914.

7. Ford ES, Ajani UA, Croft JB, et al. Explaining the decrease in U.S. deaths from coronary disease, 1980-2000. N Engl J Med. 2007;356 (23):2388-98.

8. Carlisle DM, Leake BD, Shapiro MF. Racial and ethnic differences in the use of invasive cardiac procedures among cardiac patients in Los Angeles County, 1986 through 1988. Am J Public Health. 1995;85(3):352-6.

9. Carlisle DM, Leake BD, Shapiro MF. Racial and ethnic disparities in the use of cardiovascular procedures: associations with type of health insurance. Am J Public Health. 1997;87(2):263-7.

10. Ayanian JZ, Udvarhelyi IS, Gatsonis CA, Pashos CL, Epstein AM. Racial differences in the use of revascularization procedures after coronary angiography. JAMA. 1993;269(20):2642-6.

11. Peterson ED, Shaw LK, DeLong ER, Pryor DB, Califf RM, Mark DB. Racial variation in the use of coronary-revascularization procedures. Are the differences real? Do they matter? N Engl J Med. 1997;336(7):480-6.

12. Lillie-Blanton M, Maddox TM, Rushing O, Mensah GA. Disparities in cardiac care: rising to the challenge of Healthy People 2010. J Am Coll Cardiol. 2004;44(3):503-8.

13. Ford E, Newman J, Deosaransingh K. Racial and ethnic differences in the use of cardiovascular procedures: findings from the California Cooperative Cardiovascular Project. Am J Public Health. 2000;90(7):1128-1134.

14. Sequist TD, Zaslavsky AM, Galloway JM, Ayanian JZ. Cardiac procedure use following acute myocardial infarction among American Indians. Am Heart J. 2006;151(4):909-914.

15. Canto JG, Taylor HA Jr, Rogers WJ, Sanderson B, Hilbe J, Barron HV. Presenting characteristics, treatment patterns, and clinical outcomes of non-black minorities in the National Registry of Myocardial Infarction 2 Am J Cardiol. 1998;82(9):1013-18.

16. United States Census Bureau,The American Indian and Alaska Native Populations: Census 2000 Brief, U.S. Department of Commerce Economics and Statistics Administration, 2002

17. Office of Statewide Health Planning and Development. Errors and acceptance: California patient discharge data reporting manual, 3rd Edition. 2000

18. Korenbrot CC, Ehlers S, Crouch JA. Disparities in hospitalizations of rural American Indians. Med Care. 2003;41(5):626-36.

19. Kressin NR, Chang BH, Hendricks A, Kazis LE. Agreement between administrative data and patients' self-reports of race/ethnicity. Am J Public Health. 2003;93(10):1734-9.

20. Indian Health Service, Office of Public Health Support. Final User Population Estimates, Fiscal Year 2006. 2006.

21. Dixon M. Access to care for American Indians and Alaska natives. In: Dixon M, Roubideaux Y, eds. Promises to keep: Public Health Policy for American Indians and Alaska natives in the 21 st century. Washington: American Public Health Association; 2001:61-87.

22. United States Government Accounting Office. Indian Health Service: Health Care Services Are Not Always Available to Native Americans. Washington: GAO-05-789. August 2005.

23. Hilborne LH, Leape LL, Kahan JP, et al. Percutaneous transluminal coronary angioplasty: a literature review and ratings of appropriateness and necessity. Publication JRA01. Santa Monica: Calif; 1991. The RAND Corporation.

24. Elixhauser A, Steiner C, Harris DR, Coffey RM. Comorbidity measures for use with administrative data. Med Care. 1998;36(1):8-27.

25. Prevalence of heart disease-United States, 2005. Morb Mortal Wkly Rep. 2007;56(6): 113-118

26. Statistics NCHS. Bridged Race Population Estimates. http://www.cdc gov/nchs/about/major/dvs/popbridge/popbridge.htm. Accessed 12/ $14 / 09$

27. Epstein AM, Weissman JS, Schneider EC, Gatsonis C, Leape LL, Piana RN. Race and gender disparities in rates of cardiac revascularization: do they reflect appropriate use of procedures or problems in quality of care? Med Care. 2003;41(11):1240-55.

28. Boden WE, O'Rourke RA, Teo KK, et al. Optimal medical therapy with or without PCI for stable coronary disease. N Engl J Med. 2007;356 (15): 1503-156.

29. Schneider EC, Leape LL, Weissman JS, Piana RN, Gatsonis C, Epstein AM. Racial differences in cardiac revascularization rates: does "overuse" explain higher rates among white patients? Ann Intern Med. 2001;135(5):328-37.

30. Leape LL, Hilborne LH, Bell R, Kamberg C, Brook RH. Underuse of cardiac procedures: do women, ethnic minorities, and the uninsured fail to receive needed revascularization? Ann Intern Med. 1999;130(3):183-92.

31. Schecter AD, Goldschmidt-Clermont PJ, McKee G, et al. Influence of gender, race, and education on patient preferences and receipt of cardiac catheterizations among coronary care unit patients. Am J Cardiol. 1996;78(9):996-1001.

32. Ibrahim SA, Whittle J, Bean-Mayberry B, Kelley ME, Good C, Conigliaro J. Racial/ethnic variations in physician recommendations for cardiac revascularization. Am J Public Health. 2003;93 (10): 1689-93. 